anthropometric measurements. By weight for age only $1 \%$ of boys but $5 \%$ of girls had severe malnutrition (less than $60 \%$ of the Harvard standard). In the second 6 months of life severe malnutrition was 10 times commoner among girls than boys. Generally boys maintained international standards of growth until about 7 months of age, but the girls' growth fell away by 4 months. Although numbers were small, under 6 months infants who were not breast fed had four times as much severe malnutrition as those who were. Over 6 months the benefit of breast feeding was less clear. There was no difference in nutritional state between infants who were exclusively breast fed and those who received supplements, which implies that supplementary feeding was inadequate in amount and may have reduced milk production by decreasing the child's sucking. There was more malnutrition among the children of mothers who had arrived recently in Dharavi than among the children of those who had lived there for more than five years.

The Dharavi data gave few surprises, but they emphasise: certain priorities for urban infant care. Prolonged breast feeding should be encouraged and supported. Putting newborn infants to the breast soon after delivery should be encouraged to provide early protection and nourishment. Top up feeds with animal or commercial milk are costly and probably do more harm than good. Supplementation with cereals and vegetables in adequate volume and with good food hygiene should be emphasised. The sex differences in malnutrition show that girls probably receive less food and health care and should be a priority group. The poor education of women and their low literacy rates are worrying since they probably limit the speed of adopting better nutritional practices. The living conditions in such slums are abysmal, but important improvements are unlikely in the present economic climate; therefore the initial emphasis must be on health education.

Urban squalor and impoverishment are not new: "The streets themselves are usually unpaved and full of holes. They are filthy and strewn with animal and vegetable refuse. Since they have neither gutters nor drains, the refuse accumulates in stagnant stinking puddles. Ventilation in the slums is inadequate owing to the hopelessly unplanned nature of these areas." So wrote Engels of a mid-nineteenth century English slum. ${ }^{\circ}$ High rates of malnutrition and infant mortality were typical of British cities during the industrial revolution and throughout the Victorian era. Improvements followed enlightened legislation, investment in housing, and social reforms. McKeown postulates that the better health was half due to improved standards of living, particularly nutrition, and one quarter each to specific environmental measures and a change in the character of disease.

The prospect for slum dwellers of impoverished countries looks bleak. Almost revolutionary measures appear necessary, but neither rising economic standards nor large investments in environmental improvements seem likely. New forms of medical practice and health care will be necessary, incorporating multidisciplinary teamwork and the practical application of technological advances together with education to stimulate community participation and self reliance. ${ }^{8}$ Chanting clichés will change nothing, but the people of the slums and shanty towns have initiative and vitality. There are no simple solutions, but with people grouped together the delivery of some forms of service becomes easier.' Effective immunisation requires vaccines preserved from excessive heat and delivered in a standard way, and in some slums $85 \%$ of children have been immunised. ${ }^{10}$ The supply of basic medicines that are cheap and effective is possible, and community based rehydration depot holders have been shown to reduce the mortality from diarrhoea. ${ }^{11}$ Practical education for the mothers and support for breast feeding are less easily organised but both are possible and valuable interventions. Only political commitment concerned with people's participation can divert the threatening deterioration in urban health.

William A M Cutting

Senior Lecturer,

University Department of Child Life and Health,

Edinburgh EH9 1UW

Professor and Head of Department of Preventive

GOPA KOTHARI

and Social Medicine,

LTM Medical College and Sion Hospital,

Bombay 400 022,

India

Correspondence to: Dr W A M Cutting.

1 Harpham T. Health and the urban poor. Health Policy and Planning 1986;1:5-8.

Donohue J. Some facts and figures on urbanisation in the developing countries. Assignment Children 1982;57/58:22-41

3 Rossi-Espagnet A. Primary health care in urban areas; reaching the urban poor in developing countries. A State-of-the-Art report by UNICEF and WHO. Geneva: World Health Organisation, 1984. (SHS $/ 84.4$.)

4 Crean JTG, Ling SC, Pearson DJ, Shaw SN, Stewart RJ, Wilson JH. Dharavi Project 1985. An investigation into patterns of infant feeding and malnutrition in the urban slum of Dharavi in Bombay. $\mathcal{f}$ Trop Pediatr 1987;33(Suppl 2): 1-30.

Reichenheim M, Ebrahim GJ. Obtaining best value for money in nutrition: an emerging new priority for the urban poor. F Trop Pediatr 1986;32:93-6.

6 Engels F, (Henderson WO, Chaloner WH, transl). The condition of the working class in England in 1844. Oxford: Blackwell, 1958.

McKeown T. The modern rise of population. London: Edward Arnold, 1976

8 Rohde JE. Why the other half dies. Assignment Children 1983;61/62:35-65.

9 Anonymous. Urban Primary Health Care. Appropriate Technology for Health, Newsletter 19. Geneva: World Health Organisation (Division of Strengthening of Health Services), 1987.

0 Parika I. Women-a most precious resource. Appropriate Technology for Health, Newsletter 19. $1987 ; 18-9$.

11 Rahman MM, Aziz KMS, Patwari Y, Munshi MH. Diarrhoeal mortality in two Bangladeshi villages with and without community-based oral rehydration therapy. Lancet 1979;ii:809-12.

\section{Medical management of fibroids}

Fibromyomata (fibroids) are common benign tumours of the uterus, giving rise to menstrual problems, iron deficiency anaemia, pelvic discomfort, infertility, and miscarriage. ${ }^{1}$ Small fibroids may not require treatment, but large or symptomatic ones are conventionally managed by hysterectomy or myomectomy. Technical difficulties may occur, particularly in women whose fibroids arise from the cervix or who have adhesions from a previous myomectomy. One of the reasons for a surgical approach was the difficulty in differentiating between uterine enlargement and ovarian neoplasia. Ultrasonography, however, has enabled the diagnosis of fibroids to be made more confidently with the exclusion of ovarian disease; an asymptomatic pelvic mass is thus no longer an absolute indication for laparotomy.

Regression of uterine fibroids has been reported after induction of a hypogonadal state during treatment with agonist analogues of luteinising hormone releasing hormone. ${ }^{2-6}$ These agents suppress ovarian activity secondary to down regulation of the pituitary, ${ }^{7}$ and the fibroids are thought to regress because of the withdrawal of oestrogen, as happens after the menopause. The agonists may be given intranasally or subcutaneously, but ovarian suppression is variable and less reproducible when the drugs are given intranasally - and irregular bleeding may occur. ${ }^{6}$ Because the 
degree of fibroid regression is dependent on the degree of oestrogen suppression, many prefer to give the drugs as a subcutaneous depot. ${ }^{56}$ Biodegradable implants given every month usually result in complete amenorrhoea, ${ }^{8}$ which is advantageous in women with heavy menstrual loss.

Despite encouraging results treatment with luteinising hormone releasing hormone analogues is not yet an alternative to an operation for most women. Complete regression is unusual, and once treatment is stopped the fibroids rapidly grow back to their original size. ${ }^{56}$ So far the treatment has been tried for only a few months, and it is not known whether long term treatment would produce permanent regression. There are, however, considerable anxieties about the theoretical adverse effects of a prolonged hypo-oestrogenic state on the mineral content of the bones. ${ }^{9}$ In addition, the immediate side effect of hot flushes may limit the acceptability of the treatment to young women, although this has not reduced compliance in the studies reported.

At present treatment of fibroids with luteinising hormone releasing hormone analogues should be limited to women approaching the natural menopause and those with medical contraindications to surgery. They may be valuable as a preoperative adjunct to surgery. In a controlled pilot study blood loss was significantly reduced at hysterectomy in a group of women pretreated for three months with goserelin. ${ }^{10}$ The cost of such treatment must be balanced against the potential reduction in operation time, the avoidance of blood transfusion, and the shorter stay in hospital that may result from preoperative shrinkage of the fibroids. But these benefits must be confirmed by randomised prospective study.

There is a considerable demand for medical treatment of fibroids from young women who wish to preserve the uterus. This is particularly important within some ethnic groups who have high prevalences of fibroids. " High doses of medrogestone have been reported to induce degenerative changes in fibroids, ${ }^{12}$ and more recently a significant reduction in fibroid volume was reported after treatment with gestrinone. ${ }^{13}$ Treatment with a combined luteinising hormone releasing hormone agonist and a non-oestrogenic progestogen such as medroxyprogesterone acetate is under investigation; the progestogen may protect against bone loss. ${ }^{14}$ Ross et al have recently suggested that the combined contraceptive pill, particularly one with a high progestogen content, may protect against the development of fibroids. ${ }^{15}$

It is not clear how luteinising hormone releasing hormone agonists induce fibroid regression. Shrinkage is most rapid during the first treatment cycle with little further decrease in size after three months, ${ }^{5}$ suggesting that reduction in blood flow may be important (W H Matta et al, Blair Bell Research Society, 1988). But there may also be a reduction in the concentration of receptors for oestradiol and progesterone (M A Lumsden et al, annual conference, Society for the Study of Fertility, 1987). Cell proliferation is under the control of growth factors, and epidermal growth factor binds to uterine muscle. ${ }^{16}$ The binding of epidermal growth factor to myometrium and fibroid tissue was significantly reduced in women treated with goserelin before surgery compared with untreated controls, ${ }^{17}$ suggesting that epidermal growth factor may mediate the effect of oestrogen on the growth of fibroids.

Future developments in the medical management of fibroids will be aided by greater understanding of their cause and nature, a research subject that has been neglected. At present treatment with agonists of luteinising hormone releasing hormone is a limited, although effective, alternative to an operation in some circumstances.

DAVID T BAIRD

MRC Clinical Research Professor of Reproductive Endocrinology Christine P West

Senior Lecturer

Department of Obstetrics and Gynaecology,

University of Edinburgh,

Centre for Reproductive Biology,

Edinburgh EH3 9EW

1 Buttram VC, Reiter RC. Uterine leiomyomata: etiology, symptomatology and management. Fertil Steril 1981;36:433-45.

2 Filicori M, Hall DA, Loughlin JS, Rivier J, Vale W, Crowley WF. A conservative approach to the management of uterine leiomyomata. Pituitary desensitization by a luteinizing hormone releasing hormone analogue. Am f Obstet Gynecol 1983;147:726-7.

3 Maheux R, Guilloteau C, Lemay A, Baeside AL, Fazekas ATA. Regression of leiomyomata uteri following hypo-estrogenism induced by repetitive luteinizing hormone-releasing hormone agonist treatment: preliminary report. Fertil Steril 1984;42:644-6.

4 Healy DL, Lawson SR, Abbott M, Baird DT, Fraser HM. Towards removing uterine fibroids without surgery: subcutaneous infusion of a luteinizing hormone-releasing hormone agonist commencing in the luteal phase. $\mathcal{F}$ Clin Endocrinol Metab 1986;63:619-25.

5 West CP, Lumsden MA, Lawson S, Williamson J, Baird DT. Shrinkage of uterine fibroids during therapy with goserelin (Zoladex): a monthly subcutaneous depot. Fertil Steril 1987;48:45-51.

6 Friedman AJ, Barbieri RL, Benacerraf BR, Schiff I. Treatment of leimyomata with intranasal or subcutaneous leuprolide, a gonadotrophin-releasing hormone agonist. Fertil Steril 1987;48: $560-4$.

7 Fraser HM, Baird DT. Clinical applications of LHRH analogues. Clin Endocrinol Metab 1987;1:43-70.

8 West CP, Baird DT. Suppression of ovarian activity by Zoladex depot (ICI 118630), a longacting luteinizing hormone releasing hormone agonist analogue. Clin Endocrinol (Oxf)
1987;25:213-20.

9 Matta WH, Shaw RW, Hesp R, Katz D. Hypogonadism induced by luteinising hormone releasing hormone agonist analogues: effects on bone density in premenopausal women.

$B r$ Med $\mathcal{F} 1987 ; 294: 1523-4$.
10 Lumsden MA, West CP, Baird DT. Goserelin therapy before surgery for uterine fibroids. Lancet 1987;i:36-7.

11 Miller NF, Lubovici PP. On the origin and development of uterine fibroids. Am $\mathcal{J}$ Obstet Gynecol 1955;70:720-39

12 Goldzieher JW, Maqueo M, Ricaud L, Aguilar JA, Canales E. Induction of degenerative changes in uterine myomas by high dose progestin therapy. Am $\mathcal{Y}$ Obstet Gynecol 1966;96:1078-87.

13 Coutinho EM, Boulanger GA, Concalves MT. Regression of uterine leiomyomata after treatment with gestrinone, an antiestrogen, antiprogesterone. Am $\mathcal{O}$ Obstet Gynecol 1986;155:761-7.

14 Lindsay R, Hart DM, Purdie D, Ferguson MM, Clark AS, Kraszewski A. Comparative effects of oestrogen and progestogen on bone loss in postmenopausal women. Clinical Science and Molecular Medicine 1978;54:193-5.

15 Ross RK, Pike MC, Vessey MP, Bull D, Yeates D, Casagrande JT. Risk factors for uterine fibroids: reduced risk associated with oral contraceptives. $\mathrm{Br} \mathrm{Med} \mathcal{f}$ 1986;293:359-62.

16 Hofmann GE, Rao CHV, Barrows GH, Schutz GS, Sanfilippo JS. Binding sites for epidermal growth factor in human uterine tissues and leiomyomas. $\mathcal{F}$ Clin Endocrinol Metab 1984;58: 880-4.

17 Lumsden MA, West CP, Bramley T, Rumgay L, Baird DT. The binding of EGF to the human uterus and leiomyomata in women rendered hypo-oestrogenic by continuous administration of an LHRH agonist. Br 7 Obstet Gynaecol 1988 (in press).

\section{Release of genetically altered viruses into the environment}

An organism's phenotype may be varied by changing its genome-for example, by altering, deleting, or adding genes. Over the past decade procedures have been developed to engineer such changes deliberately. The selection of natural variants and breeding for particular traits have become commonplace in agriculture, forestry, aquaculture, and animal husbandry. Modern genetic engineering now offers the additional opportunity to obtain change by specifically modifying (adding, replacing, or deleting) a particular sequence of genetic information, by introducing a synthetic gene, or by introducing genes from a source that would not otherwise be interactive with that organism.

Ethical and moral issues are raised by these technologies, particularly as they begin to be applied to higher organisms such as mammals. Most of the genetic information in such complex organisms is unknown and unexplored. Because of this (and some technical difficulties) there are few, if any, opportunities to make precise genetic changes in the genomes of higher organisms and to obtain riskless, predictive results. This will change with time: nascent programmes of research 